\title{
¿Podría el hantavirus Seúl ser una etiología de la enfermedad febril aguda indiferenciada en Colombia?
}

\author{
Carlos Ramiro Silva-Ramos ${ }^{\circledR[0}$ Esp; Álvaro A Faccini-Martínez ${ }^{2,3} \bowtie(\mathbb{0})$ Ph.D.
}

\begin{abstract}
${ }^{1}$ Pontificia Universidad Javeriana, Facultad de Ciencias, Departamento de Microbiología, Grupo de Enfermedades Infecciosas, Bogotá, Colombia.

University of Texas Medical Branch, Pathology Department, Galveston, TX, EE.UU.;

${ }^{3}$ Asociación Colombiana de Infectología, Comité de Medicina Tropical, Zoonosis y Medicina del viajero, Bogotá, Colombia.

*Correspondencia: afaccini@gmail.com
\end{abstract}

Recibido: Enero 2021; Aceptado: Febrero 2021; Publicado: Febrero 2021.

Los hantavirus se clasifican en dos grupos principales, hantavirus del Viejo Mundo' y del 'Nuevo Mundo' debido a la distribución geográfica de sus reservorios (roedores) (1). Los hantavirus del Viejo Mundo (por ejemplo, virus Hantaan, Seúl, Puumala, entre otros) causan fiebre hemorrágica con síndrome renal (HFRS, por sus siglas en inglés), mientras que los hantavirus del Nuevo Mundo (por ejemplo, virus Sin Nombre, Andes, entre otros) afectan principalmente al pulmón causando el síndrome pulmonar por hantavirus (HPS, por sus sigla en inglés) (1).

El virus de Seúl (SEOV), un hantavirus del "Viejo Mundo", es, además, el único hantavirus detectado en varios países del mundo (2), y la infección en las zonas urbanas se transmite a los seres humanos, principalmente, por el contacto con especies de roedores sinantrópicos del género Rattus (como Rattus novergicus), sin embargo, se han descrito otras formas de infecciones relacionadas a casos adquiridos dentro del laboratorio (3).

SEOV-HFRS hace parte de la etiología de la enfermedad febril, a menudo subdiagnosticada, debido a su presentación clínica generalmente leve y atípica, que tiene un curso más corto que otras infecciones por hantavirus y la disfunción renal se asocia a oliguria $(1,2)$. Otras manifestaciones clínicas como síntomas abdominales graves y disfunción hepática pueden ser más comunes que las alteraciones renales (3).

Además del continente asiático, se han encontrado evidencias moleculares y serológicas de SEOV en ratas usadas como mascotas y pacientes febriles en Europa, Oceanía, África y América, lo que convierte a SEOV en el único hantavirus ampliamente distribuido en todo el mundo. En América del Sur, puntualmente en Brasil, se han encontrado sueros humanos positivos para SEOV durante 1994, y también existe evidencia de la circulación del virus en Argentina y Perú $(4,5,6)$.

Muchas investigaciones tratan de confirmar la etiología de las enfermedades febriles agudas en todo el mundo, sin embargo, usualmente, en más de la mitad de los casos esta no es confirmada, ya que los métodos de diagnóstico difícilmente pueden incluir todos los patógenos posibles; sin embargo, los agentes emergentes necesitan ser considerados, uno de ellos podría ser SEOV. 
Una de las etiologías que causa enfermedad febril aguda y se puede confundir con SEOV-HFRS es la leptospirosis, ya que ambas comparten características clínicas y epidemiológicas: ambas son enfermedades febriles asociadas con daño renal, ambas se distribuyen principalmente en zonas tropicales y subtropicales, y ambas son infecciones transmitidas por roedores; Así, el diagnóstico equívoco usualmente es común. Una publicación brasileña confirma esta preocupación, en la cual se describieron casos de hantavirus del "Viejo Mundo" clínicamente e inicialmente como leptospirosis antes de la confirmación por laboratorio (5). También hay publicaciones en las que ambos agentes infecciosos, Hantavirus y Leptospira, pueden coexistir en el mismo huésped y desarrollar coinfecciones (7).

En Colombia, se ha encontrado evidencia serológica de hantavirus en humanos desde 2007, año en el que un estudio de la enfermedad febril aguda no palúdica en el "Urabá antioqueño" evidenció la exposición frente a Hantavirus en dos pacientes febriles, demostrando la circulación de hantavirus entre humanos (8). Posteriormente, entre 2012 y 2013, un estudio realizado en el departamento de Córdoba evidenció la infección por hantavirus en seis pacientes, dos de ellos con coinfecciones con el virus del dengue y Leptospira, siendo uno de ellos mortal; ninguno desarrolló características clínicas o de laboratorio compatibles con el típico HPS del 'Nuevo Mundo" (9). Además, se informó de un nuevo caso en Montería (capital de Córdoba); este paciente demostró seroconversión frente al virus Sin Nombre (SNV), no obstante, presentó síntomas respiratorios leves, siendo inicialmente diagnosticado como leptospirosis con síntomas clínicos no asociados a HPS (10).

Estos datos preliminares pueden sugerir que la enfermedad por hantavirus en este departamento del Caribe podría ser leve y no clínicamente compatible con el HPS causado por hantavirus del Nuevo Mundo, incluso con un diagnóstico serológico positivo para el SNV, el cual puede presentar reacción cruzada entre las especies de hantavirus (11), siendo posible que un hantavirus del Viejo Mundo pueda estar involucrado en estos casos febriles. Curiosamente, un estudio realizado entre 2007 y 2009 en el departamento de Sucre (frontera norte de Córdoba) evidenció seropositividad para el SNV en roedores de las familias Muridae y Cricetidae, incluyendo especies del género Mus spp. y Rattus spp., demostrando que al menos un hantavirus está circulando en estos roedores sinantrópicos (12).

Finalmente, en 2013, se realizó otro estudio en la región de la Orinoquía, en la que se incluyeron pacientes febriles del departamento del Meta, tres de ellos seroconvirtieron al SNV y siete más evidenciaron seropositividad, lo que sugiere una exposición previa al Hantavirus. Al revisar los datos clínicos de los tres pacientes que presentaron seroconversión se evidenciaron características comunes de la enfermedad febril aguda, con síntomas generales inespecíficos y síntomas respiratorios leves; los hallazgos de laboratorio incluyeron aumento del hematocrito, creatinina y recuentos de leucocitos, trombocitopenia y enzimas hepáticas elevadas (13).

Los datos anteriores reafirman la presencia de Hantavirus en Colombia y la importancia de considerarlo en el diagnóstico diferencial de la enfermedad febril aguda indiferenciada. Sin embargo, el diagnóstico preciso de un hantavirus típico del Nuevo Mundo todavía está en duda, y probablemente no está involucrado en estos casos, ya que las características clínicas del HPS no están presentes. Por el contrario, la infección por hantavirus en Colombia podría tener un curso más leve y atípico. De esta manera, sumado al hecho de que el SEOV es el hantavirus del Viejo Mundo de mayor distribución geográfica, y teniendo en cuenta su curso clínico atípico y leve, creemos importante considerar a SEOV como uno de los posibles agentes etiológicos de las infecciones por hantavirus en Colombia, destacando la importancia de buscarlo entre los pacientes febriles. 


\section{REFERENCIAS}

1. Jonsson $C B$, Figueiredo $L T$, Vapalahti O. A Global Perspective on Hantavirus Ecology, Epidemiology, and Disease. Clin Microbiol Rev, 2010; 23(2):412-441. https://doi. org/10.1128/CMR.00062-09

2. Clement J, LeDuc JW, McElhinney LM, Reynes J, Van Ranst $\mathrm{M}$, Calisher $\mathrm{CH}$. Clinical Characteristics of Ratborne Seoul Hantavirus Disease. Emerg Infect Dis. 2019; 25(2):387-388. https://dx.doi. org/10.3201/eid2502.181643

3. Kim YS, Ahn C, Han JS, Kim S, Lee JS, Lee PW. Hemorrhagic fever with renal syndrome caused by the Seoul virus. Nefrón. 1995; 71(4):419-427. https://doi. org/10.1159/000188762

4. García PM, Percy S, Herrera AL, Donaires F, Álvarez C, Arrasco J, et al. Confirmación Etiologic de los dos primeros casos de Hantavirosis Humana en Perú. Rev Peru Med Exp Salud Publica. 2011; 28(3):564-570. https://doi.org/10.17843/ rpmesp.2011.283.542

5. Hindrichsen S, Medeiros A, Clement J, Leirs $H$, Mc Kenna $P$, Matthys $P$, et al. Hantavirus infection in Brazilian patients from Recife with suspected leptospirosis. Lancet, 1993; 341(8836):50. https://doi. org/10.1016/0140-6736(93)92523-V

6. Seijo A, Pini N, Levis $S$, Coto $H$, Deodato B, Cernigoi B, et al. Study of Hantavirus seoul in a human and rodent population from a marginal area in Buenos Aires City. Medicina (B Aires). 2003; 63(3):193-196. https:// pubmed.ncbi.nlm.nih.gov/12876901/

7. Clement J, Esbroeck M V, Lagrou K, Verschueren J, Sunil-Chandra NP, Ranst M V. Leptospirosis versus hantavirus infections in the Netherlands and in Belgium, 2000 to 2014. Euro Surveill. 2014; 19(38):20912. https://doi.org/10.2807/1560-7917. ES2014.19.38.20912
8. Arroyave $E$, Londoño AF, Quintero JC, Agudelo-Florez P, Arboleda M, Díaz FJ, Rodas JD. Etiología y caracterización epidemiológica del síndrome febril no palúdico en tres municipios del Urabá antioqueño, Colombia. Biomedica. 2013; 33(Sup1):99-107. https://doi.org/10.7705/ biomedica.v33i0.734

9. Mattar S, Tique V, Miranda J, Montes E, Garzón D. Undifferentiated tropical febrile illness in Cordoba, Colombia: Not everything is dengue. J Infect Public Health. 2017; 10(5):507-512. https://pubmed.ncbi.nlm. nih.gov/28162961/

10. Mattar S, Garzon D, Tadeu L, Faccini-Martínez AA, Mills JN. Serological diagnosis of hantavirus pulmonary syndrome in a febrile patient in Colombia. Int J Infect Dis. 2014; 25:201-203. https://doi.org/10.1016/j. ijid.2014.03.1396

11. Lederer S, Lattwein E, Hanke M, Sonnenberg $\mathrm{K}$, Stoecker W, et al. Correction: Indirect Immunofluorescence Assay for the Simultaneous Detection of Antibodies against Clinically Important Old and New World Hantaviruses. PLOS Neglected Tropical Diseases. 2020; 14(11):e0008864. https:// doi.org/10.1371/journal.pntd.0008864

12. Arroyo MS, Corrales AH, Perez JJ, Alvarez GL, Castellar MA, Blanco TP. Evidencia serológica de infección por hantavirus (Bunyaviridae: Hantavirus) en roedores del Departamento de Sucre, Colombia. Rev Salud Pública. 2012; 14(5): 755-764. https://revistas.unal. edu.co/index.php/revsaludpublica/article/ view/22357

13. Sánchez L, Mattar S, Rodriguez D, Tique V, Rodríguez I. First serological evidence of hantavirus infection in humans from the Orinoquia region of Colombia. Braz J Infect Dis. 2016; 20(5):507-508. https://doi. org/10.1016/j.bjid.2016.05.006 